Artículo. Número especial

'Etnografías de la pandemia por coronavirus'

\section{El control en los tiempos del coronavirus}

\section{ALEJANDRO GEREZ GÓMEZ ${ }^{1}$}

(i) https://orcid.org/0000-0002-3157-0298

Universitat Autònoma de Barcelona, España

\section{ANAÍS MAC MILLAN HERNÁNDEZ²}

https://orcid.org/0000-0001-6711-5185

Universitat Autònoma de Barcelona, España

\section{GAITÁN ESTUPIÑÁ VILAS 3}

https://orcid.org/0000-0002-5382-9889

Universitat Autònoma de Barcelona, España

\section{HELENA SISTAC GARICA ${ }^{4}$}

https://orcid.org/0000-0002-2798-2484

Universitat Autònoma de Barcelona, España

\section{JÚLIA ALBOS ISCLA ${ }^{5}$}

(i) https://orcid.org/0000-0001-7011-9718 Universitat Autònoma de Barcelona, España

\section{NATÀLIA MARTÍ ÁLVAREZ ${ }^{6}$}

https://orcid.org/0000-0001-7674-3124

Universitat Autònoma de Barcelona, España

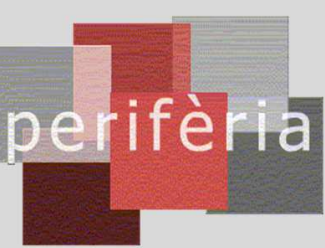

revistes.uab.cat/periferia

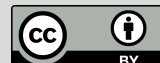

Junio 2020

Para citar este artículo:

Gerez, A., Mac Millan, A., Estupiñá, G., Sistac, H., Albós, J., Martí, N. (2020). El control en los tiempos del coronavirus. Perifèria, revista de recerca i formació en antropologia, 25(2), pp.203-215, https://doi.org/10.5565/rev/periferia.799

\footnotetext{
1 Contacto: Alejandro Gerez Gómez - Alejandro.Gerez@e-campus.uab.cat

2 Contacto: Anaís Mac Millan Hernández - anais.macmillan@e-campus.uab.cat

3 Contacto: Gaitán Estupiñá Vilas - alvargaitan.estupina@e-campus.uab.cat

4 Contacto: Helena Sistac Garcia - Helena.Sistac@e-campus.uab.cat

5 Contacto: Júlia Albos Iscla - Julia.Albos@e-campus.uab.cat

6 Contacto: Natàlia Martí Álvarez - Natalia.MartiA@e-campus.uab.cat
} 


\section{Resumen}

Bajo el estado de alarma para frenar la pandemia de COVID-19 en España se han recortado libertades personales y civiles a través del decreto de confinamiento obligatorio. El control social se ha impuesto por ley, pero también ha operado un control desde los ciudadanos para los ciudadanos. Este artículo, fruto de entrevistas y encuestas, tiene por objetivo analizar de qué manera la población ha aceptado el control social y en qué medida ha contribuido al mismo. En el presente texto se muestra la diversidad de reacciones y comportamientos en los procesos de asimilación de las nuevas medidas.

Palabras clave: Control; Espacio público; Pandemia; Prácticas sociales; Control social; COVID-19.

\section{Abstract: Control during coronavirus pandemic}

Under the State of alarm aiming to halt the spread of COVID-19, personal and civil liberties have been cut through the national lockdown. Social control has been imposed by law and restrictions, but control has also operated from citizens to citizens. Based on the results of interviews and surveys we've done, we can point out how the population has accepted social control and how they have contributed to the constitution of this state. This research shows the diversity of reactions and behaviors in the assimilation of the new measures.

Keywords: Control; Public Space; Pandemic; Social Practices; Social Control; COVID-19.

\section{Introducción}

Este trabajo parte de la situación de alarma sociosanitaria sobrevenida por la aparición de un invitado sorpresa en nuestra cotidianeidad y los cambios que ha traído aparejados. Queremos profundizar sobre cómo el control se ha adueñado de nuestras vidas en el contexto de la pandemia de COVID-19 que vivimos. Por ello, centrando nuestra investigación en Cataluña, nos interesa explorar cómo socialmente se ha generado el estado de alarma y con ello el miedo al virus, integrando las normas 
de confinamiento impuestas. Y en consonancia, cómo se han adquirido por parte de la población española nuevos roles de control y vigilancia.

Este texto ha de contribuir a una mayor comprensión de las repercusiones sociales con respecto a las medidas de confinamiento y distancia social aplicadas por el Gobierno de España durante la crisis. Para ello analizamos tres tipos de control: el policial, el vecinal y el control del espacio. También nos fijamos en el papel que han desempeñado los medios de comunicación en la aceptación e integración de las medidas por parte de la población.

\section{Acercamientos teóricos}

En la situación de emergencia actual se han generado discursos que han legitimado nuevas formas de control de los espacios y de los cuerpos cambiando nuestra cotidianidad y modificando los comportamientos permitidos. En este contexto, es necesario analizar los procesos y mecánicas a partir de los cuales la sociedad asimila las restricciones y reproduce las nuevas prácticas. Partiendo de las aportaciones de Naomi Klein y La Doctrina del Shock, como ideología y técnica implementada por los estados, que aprovechando momentos de crisis instauran nuevas medidas y reformas en contra de las libertades personales, atacando a los más vulnerables y favoreciendo a las potencias económicas y la privatización (Klein, 2009). Preciado comenta que "la COVID-19 ha legitimado y extendido esas prácticas estatales de biovigilancia y control digital normalizándolas y haciéndolas 'necesarias' para mantener una cierta idea de la inmunidad." (Preciado, 2020, p.178). De esta forma podemos observar que en poco tiempo se han ido implementando nuevos mecanismos y prácticas asumidas con la misma rapidez. En referencia al libro de George Orwell, Berardi (2020, p.45) señala que podemos ver el virus como un "COVID-1984" pues no hay mejor condición para la formación de regímenes totalitarios que las situaciones de emergencia extrema, donde la supervivencia de todos está en juego.

Este proceso de asimilación se sustenta bajo la idea del contrato social de Rousseau (1762), que plantea la existencia de un acuerdo implícito entre los ciudadanos y el Estado. Existen diversos mecanismos para asegurar el cumplimiento de los deberes exigidos por el Estado. Por un lado, Rousseau, considera la vigilancia y el castigo como elementos esenciales para la obediencia. Siguiendo esta línea, Foucault (1986) 
establece el autocontrol como una de las principales herramientas de vigilancia, comparando la sociedad con el panóptico, sostiene que acatamos las normas debido a la constante sensación de vigilancia y control. Esta idea es reforzada por B. C. Han (2014), el cual traslada la metáfora al mismo individuo como agente controlador.

Este sentimiento en la actualidad se ve reforzado gracias a los medios de comunicación y las redes sociales, que se convierten en elemento esencial en la constitución del imaginario colectivo, Borges sostiene que los medios de comunicación construyen valores, actitudes y modelos de conducta (2011, p.80). En palabras de Chomsky, los medios practican "la fabricación de consenso" (2003, p.7), que se refiere al poder que tienen las empresas de comunicación para crear una opinión pública que tenga una incidencia directa en la aplicación y aceptación de políticas públicas.

En cuanto a los espacios públicos, Manuel Delgado lo define desde su valor ideológico, en tanto que "se materializan diversas categorías abstractas" (2011, p. 10), a partir de las cuales se constituyen ideales democratizadores del orden, libertad e igualdad que inevitablemente se sustentan en procesos de exclusión, discriminación y dinámicas de poder. De esta forma el espacio público es lo que viven y perciben los ciudadanos, sin embargo, no es un espacio totalmente libre de uso y práctica ya que se constituye bajo procesos de homogeneización a partir de un discurso, "impuesto generalmente a través de una violencia inherente o incluso en algunos momentos (considerados de excepción) mediante la violencia abierta" (Bono, 2014, n.d.). Por lo tanto, el espacio se concibe con un único fin y todos aquellos usos no normativos son castigados. Con relación a los cuerpos, Žižek argumenta cómo en una epidemia podemos observar que pueden darse circunstancias que afecten a nuestras relaciones sociales "en las que debemos aprender a controlarnos y disciplinarnos" (Žižek, 2020, p.25).

\section{Metodología}

Para desarrollar esta tarea nos hemos basado en una metodología que combina la recogida de datos cualitativa y cuantitativa. Por un lado, se han realizado 10 entrevistas semiestructuradas a personas que viven en Catalunya entre abril y mayo del 2020, en las que se han registrado y luego analizado los datos empíricos 
que proporcionaron los entrevistados. Cabe señalar que se realizaron permisos informados, siempre identificados como estudiantes e investigadores y que las identidades de los entrevistados han sido protegidas usando seudónimos. Por otro lado, se ha diseñado una encuesta a través de Google Forms a la que respondieron 397 personas, facilitando una muestra heterogénea en términos de edad, profesión y variables socioeconómicas. Para la gestión de los datos se ha utilizado un programa de análisis cualitativo (Atlas.ti) y el servicio de gestión de datos que ofrece Google para el análisis de la encuesta.

\section{Formas de control}

\section{Control policial}

Una de nuestras preguntas era si sería necesario aumentar la presencia policial con el objetivo de dar cumplimiento al nuevo estado. Pero hemos comprobado que no se ha dado ese aumento porque la población ha respetado las normas de forma generalizada. Una de las entrevistas que realizamos fue a un integrante de la policía autonómica de Cataluña, Mossos d’Esquadra, quien nos confirmó que "es un porcentaje muy bajo que no cumple con el sentido común y con la norma que nos han intentado imponer desde arriba" (Carlos, entrevista, 15 mayo 2020). Por otra parte, hemos visto a partir de la encuesta y las entrevistas que la percepción sobre la presencia de fuerzas de seguridad en el espacio público varía con relación al territorio donde se vive. En otra entrevista, Claudia (entrevista, 28 abril 2020) nos explicó que tuvo dos encuentros con la policía y uno de ellos acabó con una sanción, pero en general no percibe un aumento de la presencia policial. Según los datos recogidos en la encuesta vemos que un $31 \%$ de los participantes han tenido un encuentro con la policía y que estos se daban durante controles rutinarios de camino al trabajo o a hacer la compra. Sin embargo, se han difundido vídeos e imágenes de abusos policiales, en este sentido, Esperanza (entrevista, 1 mayo 2020) piensa que la policía ha realizado una buena labor:

Una tarea ejemplar. Son una herramienta. Es como si me preguntas si creo que el arma que lleva el policía ha cumplido su misión de intimidar cuando ha parado a alguien. Sí. Y la multa también. El policía, la multa, la pistola, el papel de la multa y el coche es lo mismo. Lo que pasa es que unos son personas y los otros 
son cosas, pero son lo mismo: una herramienta destinada al control de la gente y el espacio público.

Por otro lado, Carlos (entrevista, 15 mayo 2020) nos explicaba que él ha intentado regirse por el sentido común y no tanto por los protocolos. Además, tanto las personas entrevistadas como las opiniones que recogimos en la encuesta coinciden en la crítica a la aplicación del confinamiento y del estado de alarma por aplicar medidas desde una visión centralizada del estado, sin atender a particularidades.

Hay distintas teorías sobre el modelo social actual que nos describen por qué no ha sido necesario aumentar el cuerpo de seguridad para garantizar el cumplimiento de las normas extraordinarias de la pandemia. Una de ellas es que vivimos inmersos en un panóptico de control y vigilancia que, mediante instituciones de confinamiento como escuelas, hospitales o cárceles, se encargan de hacernos interiorizar el cumplimiento de las normas impuestas desde el estado, gracias a un proceso de educación basado en la obediencia y el castigo (Foucault, 1986).

Con el capitalismo, se ha configurado un nuevo un sistema inteligente de auto explotación con una falsa percepción de la libertad, pero en el que nos convertimos en nuestros propios vigilantes y nuestra propia policía, un nuevo panóptico personal. Este es capaz de manipular las propias emociones con el objetivo de que continuemos sumisos, pero sin coacciones y por propia voluntad (B. C. Han, 2014).

\section{Control vecinal}

Durante este confinamiento hemos visto cómo las personas han cogido el papel de vigilantes. Vemos cómo los balcones se han convertido en un lugar de control social, siendo el único espacio exterior permitido y cumpliendo una función socializadora, y también una función de vigilancia. Pere (entrevista, 12 abril 2020) nos comenta que siente rabia hacia las personas que se dedican a hacer de "policía de balcón". Explica que no entiende cómo unas personas pueden decir a otras lo que tienen que hacer, ya que puede ser que a los cinco minutos la persona que abuchea tenga que salir $y$ se pregunta si también será abucheado por otros. En este sentido vemos la contemporaneidad del contrato social. Cuando un individuo ataca el derecho social se le juzgará más como enemigo que como ciudadano (Rousseau, 1762). Por ejemplo, se viralizó un vídeo grabado desde un balcón y difundido en Twitter, de una chica que mientras es detenida por dos policías nacionales, los vecinos le chillan y le 
insultan, diciendo cosas como: "estás poniendo en riesgo a la gente payasa!" o "todos aquí metidos ... una semana ya7". Vemos como en el momento que se rompe la norma aceptada la persona merece ser castigada.

Siguiendo esta idea, una de las cosas que hemos podido documentar es el hecho que todas las personas que hemos entrevistado, independientemente de las ideas que tuvieran sobre el confinamiento y el estado de alarma, han asumido las medidas decretadas por el gobierno, ya sea por voluntad propia o por la sensación de control y vigilancia o el miedo a la sanción. En estas circunstancias las relaciones sociales se han establecido desde el miedo hacia aquellas personas que pueden transmitir el COVID-19. No obstante, de manera paulatina el miedo se ha expandido a todos los cuerpos, potencialmente todos somos peligrosos. Además, hemos visto cómo el miedo se proyecta hacia los objetos, tal y como nos relata Claudia (entrevista, 28 abril 2020) quien ha interiorizado las normas higiénicas de lavarse constantemente las manos y mantener la distancia interpersonal. En este aspecto, Esperanza (entrevista, 1 mayo 2020) relata sorprendida cómo en un entorno aislado vio a un chico corriendo delante de su casa con un pañuelo a modo de mascarilla. O cómo una vecina en sus paseos diarios se paraba unos metros antes de llegar a la casa y daba la vuelta. Incluso ella, que se considera una persona disidente, se sorprendió a sí misma con la mascarilla puesta, a pesar de que su uso no era obligatorio, al ver en el supermercado a un chico sin ella. Estos hechos le hacen pensar hasta qué punto hemos interiorizado estas medidas.

\section{Espacio}

El espacio público está sujeto a unas mecánicas de control y regulación y consideramos que en el contexto del COVID-19 se han visto reforzadas a causa de las restricciones derivadas del confinamiento y el distanciamiento social. Además, se ha producido una notable transformación respecto a cómo lo vivimos. Nos hemos visto obligados a acatar nuevas medidas y normas en favor de nuestra propia seguridad cambiando nuestras costumbres significativamente.

Teniendo en cuenta que los espacios públicos, bajo los ideales democráticos y por lo tanto de dominación y discriminación, están diseñados para ser accesibles (cómodos,

7 Twitter: @maxpradera (20/03/2020). "Quieres ir por libre? ESTO es lo que te espera". 
seguros, etc.), para experimentar y crear lazos sociales (Pires, 2007) y como resultado de una crisis (o cualquier perturbación) las percepciones y aproximaciones se ven alteradas y modificadas, generando nuevos patrones, prácticas y reforzando las desigualdades (Honey-Rosés et al., 2020). En este aspecto, Esperanza (entrevista, 1 mayo 2020) se plantea hasta qué punto el espacio público ha sido secuestrado, ya que una de las cosas que más le ha impactado al salir de casa ha sido el hecho de no poder ir a recoger agua ya que las fuentes, al igual que los parques, estaban acordonadas por la policía. En relación con estos usos normativos, Carlos (entrevista, 15 mayo 2020) nos explica los problemas que ha tenido para poder ver a sus hijas que residen en Andorra. Él reside en un pueblo cerca de la frontera y veía que había muchas personas que la cruzaban por motivos laborales. No entendía cómo podía ser que hubiera algunos pasos fronterizos regulados y otros que no lo estuvieran.

La mayoría de las personas entrevistadas manifiestan miedo a no poder recuperar algunas de las libertades, o bien en relación con las formas de opresión, dominio y exclusión que pueden comportar la vacuna y la aceptación de las medidas de control y de la "nueva normalidad". Y pesar de que estamos viendo que se están retomando los espacios de manera similar a como lo hacíamos antes, la reticencia a establecer contacto con personas desconocidas, sentirse incómodo cuando alguien quiebra la distancia o estornuda, serán actitudes que nos acompañarán durante largo tiempo como consecuencia.

\section{Medios de comunicación y redes sociales}

Ya en 1922 Walter Lippman expuso en su libro La opinión pública ([1922]2004) que los medios de comunicación de masas construyen un pseudoentorno en el cual se orienta la mayoría de la gente. Los medios nos hacen llegar la información que necesitamos para nuestra vida cotidiana, o más bien, la que deciden que necesitamos. En el acto de escoger qué información dar, y en qué orden, están programando y organizando jerárquicamente los temas sobre los que se va a hablar en la calle y sobre los que no se va a hablar mayoritariamente. Pero también se construyen valores, actitudes y modelos de conducta (Borges, 2011, p.80). En este aspecto, María (entrevista, 21 abril 2020) nos explica que ella y su madre han dejado de ver la televisión y de consultar los medios de comunicación porque sentían una sobreinformación con relación al coronavirus que hacía que la gente tuviera más 
miedo. Por otro lado, también nos explica cómo piensa que esto ha hecho que no se informara adecuadamente de las cosas que eran importantes. Nuestra encuesta reafirma esta idea, un $92,7 \%$ considera que los medios han repercutido en los comportamientos sociales y el $73,8 \%$ cree que han contribuido a generar pánico.

La crisis sanitaria requería una información clara y actualizada a fin de evitar mayor número de contagios y muertes, pero lo que hemos visto ha sido un bombardeo sistemático $24 / 7$ de informaciones catastrofistas. Existe una diferencia entre informar adecuadamente a la población y generar un estado de alarma social y miedo permanente. Usando la herramienta del pánico los medios han ayudado a construir las actitudes y los modelos de conducta que supuestamente se necesitaban para manejar esta situación. Por ello se nos muestran videos e imágenes de personas saltándose el confinamiento, recibiendo sanciones y castigos. Y se utilizan eslóganes como el del grupo de comunicación español Atresmedia: "Somos un gran país. Ya queda menos para disfrutar de él". O incluso la campaña de concienciación del Gobierno de España, "este virus lo paramos unidos", que nos remiten a las técnicas expuestas por Chomsky (2003) para la fabricación de consenso. Los medios de comunicación de masas están financiados y sustentados por todo tipo de empresas privadas (Camps, 1995), lo que hace que su actuación y criterio deje muchas dudas que despejar para la mayoría de población (Borges, 2011).

A pesar de que las redes sociales se han convertido en un contrapoder, hay una lucha ideológica para tener más presencia, obtener un mayor alcance en la difusión de los mensajes y controlar el contenido. Así, destacamos el rol de las redes sociales y los medios de comunicación en la ideas y percepciones colectivas que tenemos respecto al acatamiento de las medidas. Ya no es necesario el aislamiento entre sujetos, sino que la máxima comunicación y exposición de la intimidad crea un nuevo estado de control con las emociones y el exceso de información como las principales herramientas del nuevo sistema político basado en la psicopolítica digital (B. C. Han, 2014). De esta forma vislumbramos el nuevo panóptico digital en el que entregamos nuestra libertad por voluntad propia, una libertad que se convierte en control y vigilancia de nuevo, esta vez mediante la comunicación y la transparencia. 


\section{Conclusiones}

A partir de lo dicho, se nos hace evidente que el confinamiento y el estado de alarma han generado cambios importantes, tanto en nuestras rutinas como en las maneras de relacionarnos. A partir de la conjunción de los materiales analizados, nos damos cuenta no solo de que las medidas de control y de distanciamiento social han sido aceptadas e incorporadas por la mayor parte de la sociedad, sino que, a su vez, estas han sido asimiladas por parte de la población civil hasta el punto de que ha habido personas que han adoptado el rol de policía y se han visto con el poder de decir a otras lo que debían o no debían hacer.

Consideramos que hay dos factores clave que han permitido esta apropiación de las medidas de control por parte de la población. Por un lado, los medios de comunicación nos han sacudido constantemente con datos, cifras y un sinfín de argumentos de expertos que han generado pánico colectivo y han mantenido a la población distraída en ciertos aspectos con el fin de redirigir a la opinión pública hacia la nueva normalidad. Por otro lado, esta nueva normalidad podría ser pautada por un régimen de vigilancia biopolítica y digital, puesto que ya existen ${ }^{8}$ propuestas de aplicaciones web para el control de la temperatura corporal, el estado de salud, las relaciones sociales o el régimen de vacunas.

Todo esto está comportando un aumento de la desigualdad social, pues no todas las personas tienen cubiertas las necesidades de higiene; algunos de los trabajos más precarios (los cuidadores, los trabajadores de las fábricas, los que limpian, los vendedores o los que recogen la basura) son los que comportan mayor riesgo de contagio a la vez que no pueden ser hechos desde casa por teletrabajo. En cambio, hemos visto a muchas personas adineradas ir a pasar la cuarentena en sus segundas residencias, lo cual hace evidente que la vulnerabilidad y la mortalidad humana no son democráticas.

Hemos documentado que toda la población, en mayor o menor media, ha acatado e interiorizado unos elementos de control social que desconocía pero que ha aceptado

8 Generalitat de Catalunya. (2020) Nova app per detectar la Covid 19 a Catalunya. Gencat. 18 marzo 2020. Recuperado de: https://web.gencat.cat/ca/actualitat/detall/Nova-app-per-detectar-la-Covid-19-aCatalunya 
por el hecho del miedo al contagio, por ser un tema de salud pública y para evitar las represalias. La comunidad científica apunta a que, cada vez con más frecuencia, virus con este grado de letalidad podrían expandirse por el mundo. Los momentos de shock son momentos en los que es más fácil recortar las libertades a través de mecanismos de control social, policial y militar. Si esta es la perspectiva que nos espera, debemos reflexionar sobre cómo las sociedades somos capaces de aceptar y/o transformar las medidas sociosanitarias sin permitir que se nos coarte la libertad ni la seguridad. Solo el tiempo nos lo dirá.

\section{Bibliografía}

Berardi, F. (2020). Crónica de la psico deflación. En VVAA, Sopa de Wuhan. (p. 3555). ASPO (Aislamiento Social Preventivo y Obligatorio). Recuperado de: http://iips.usac.edu.gt/wp-content/uploads/2020/03/Sopa-de-WuhanASPO.pdf

Bono Cremades, J. (2014). Manuel Delgado, El espacio público como representación. [Blog] cargocollective. Septiembre de 2014. Recuperado de: https://cargocollective.com/jbono/BLOG/filter/bausophie/Manuel-DelgadoEl-espacio-publico-como-representacion

Borges, R. F. R. (2011). Esfera pública y medios de comunicación. La contribución de los media a la construcción de la ciudadanía democrática. Daimon Revista Internacional de Filosofía, 79-93.

Camps, V. (1995). El lugar de la ética en los medios de comunicación. En E. Bonete, Éticas de la información y deontologías del periodismo (pp. 53-64). Madrid: Tecnos.

Castillo, C. (2018). ¿Quién controla los medios? No quieren que lo sepas, pero hay formas de rastrearlo. El público. 30 de enero de 2018. Recuperado de: https://www.publico.es/politica/controla-medios-no-quieren-sepas-hayformas-rastrearlo.html

Chomsky, N. (2003). El control de los medios de comunicación. Recuperado de: https://cronicon.net/paginas/Documentos/paq2/No.31.pdf 
Delgado, M. (2011). El espacio público como ideología. Madrid: Los Libros de la Catarata.

Foucault, M. (1986). Vigilar y castigar. Nacimiento de la prisión. Buenos Aires: Siglo XXI

Guardiola, I. (2020). La Nova Normalitat. Mayo de 2020 [Video]. Recuperado de: https://www.youtube.com/watch?v=vTepSNeSv0A

Han, B.C. (2014) La Crisis de la Libertad. Psicopolítica: Neoliberalismo y nuevas técnicas de poder. Barcelona: Herder.

Han, B.C. (2020). 9 definiciones sobre el coronavirus de Byung-Chul Han, el filósofo surcoreano que seduce al mundo. 20 de mayo de 2020. Recuperado de: https://www.eluniverso.com/noticias/2020/05/20/nota/7846488/9definiciones-sobre-coronavirus-byung-chul-han-filosofo-surcoreano

Honey-Roses, J., Anguelovski, I., Bohigas, J., Chireh, V., Daher, C., Konijnendijk, C., ... \& Oscilowicz, E. (2020). The impact of COVID-19 on public space: a review of the emerging questions. https://doi.org/10.31219/osf.io/rf7xa

Infosalus.2020). Sanidad desaconseja utilizar guantes para salir a la calle. 6 de abril de 2020. Recuperado de: https://www.infosalus.com/asistencia/noticiasanidad-desaconseja-uso-guantes-calle-protegerse-coronavirus20200406141049.html

Klein, N. (2009). The shock doctrine. New York: Picador/H. Holt and Co.

Lippmann, W. ([1922]2004). La opinión pública. Madrid: Langre.

NextIBS. (2020). Lemas de las empresas contra el coronavirus. 25 de mayo de 2020. Recuperado de: https://www.nextibs.com/los-lemas-de-lasempresas-contra-el-coronavirus-asi-han-cambiado-sus-campanaspublicitarias/

Pires, T. (2007). Ciudad de muros. Barcelona: Gedisa ed.

Preciado, P. B. (2020). Aprendiendo del virus. En VVAA, Sopa de Wuhan. (p. 163185). ASPO (Aislamiento Social Preventivo y Obligatorio). Recuperado de: http://iips.usac.edu.gt/wp-content/uploads/2020/03/Sopa-de-WuhanASPO.pdf 
Rousseau, J.J. ([1762]1975). El contrato social: o los principios del derecho político. Madrid: Espasa Calpe.

Žižek, S. (2020, febrero 27). El coronavirus es un golpe al capitalismo a lo Kill Bill... En VVAA, Sopa de Wuhan. (p. 21-29). ASPO (Aislamiento Social Preventivo y Obligatorio). Recuperado de:_http://iips.usac.edu.gt/wpcontent/uploads/2020/03/Sopa-de-Wuhan-ASPO.pdf 